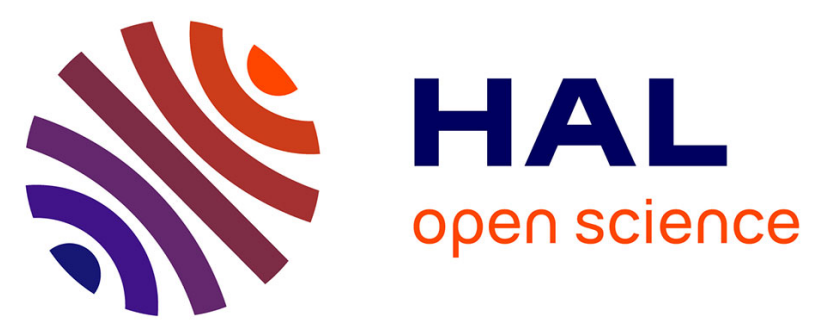

\title{
Atazanavir plasma concentrations are impaired in HIV-1-infected adults simultaneously taking a methadone oral solution in a once-daily observed therapy setting
}

Annette Haberl, Manfred Moesch, Gabriele Nisius, Christoph Stephan, Markus Bickel, Pavel Khaykin, Michael Kurowski, Reinhard Brodt, Nils Hentig

\section{- To cite this version:}

Annette Haberl, Manfred Moesch, Gabriele Nisius, Christoph Stephan, Markus Bickel, et al.. Atazanavir plasma concentrations are impaired in HIV-1-infected adults simultaneously taking a methadone oral solution in a once-daily observed therapy setting. European Journal of Clinical Pharmacology, 2009, 66 (4), pp.375-381. 10.1007/s00228-009-0767-8 . hal-00550171

\section{HAL Id: hal-00550171 \\ https://hal.science/hal-00550171}

Submitted on 24 Dec 2010

HAL is a multi-disciplinary open access archive for the deposit and dissemination of scientific research documents, whether they are published or not. The documents may come from teaching and research institutions in France or abroad, or from public or private research centers.
L'archive ouverte pluridisciplinaire $\mathbf{H A L}$, est destinée au dépôt et à la diffusion de documents scientifiques de niveau recherche, publiés ou non, émanant des établissements d'enseignement et de recherche français ou étrangers, des laboratoires publics ou privés. 


\title{
Atazanavir plasma concentrations are impaired in HIV-1-infected adults simultaneously taking a methadone oral solution in a once-daily observed therapy setting
}

\author{
Annette Haberl • Manfred Moesch • Gabriele Nisius • \\ Christoph Stephan • Markus Bickel • Pavel Khaykin • \\ Michael Kurowski • Reinhard Brodt • Nils von Hentig
}

Received: 18 September 2009 / Accepted: 18 November 2009/Published online: 24 December 2009

(C) Springer-Verlag 2009

\begin{abstract}
Objective The human immundeficiency virus (HIV) protease inhibitor atazanavir is often used in once-daily observed therapy of methadone substituted former opiate drug users. We performed a matched-pairs analysis on 24 patients (12 men/women) taking atazanavir/ritonavir 300/100 mg daily plus reverse transcriptase inhibitors, with $(n=12)$ or without $(n=12)$ methadone co-administration.

Methods Twenty-four-hour pharmacokinetic profiles of atazanavir/ritonavir were assessed at steady-state and measured by liquid chromatography-tandem mass spectrometry. The geometric mean (GM, $t$ test) minimum and maximum plasma drug concentrations $\left(\mathrm{C}_{\min }, \mathrm{C}_{\max }\right)$, area under the concentration-time curve (AUC), and total clearance $\left(\mathrm{CL}_{\text {total }}\right)$ were compared between the groups of pairs, which were matched for age, sex, weight, and ethnicity.

Results The GM $[90 \%$ confidence interval (CI)] of the atazanavir $\mathrm{C}_{\min }, \mathrm{C}_{\max }$, and $\mathrm{AUC}$ of patients taking the methadone oral solution at doses of $20-175 \mathrm{mg} /$ day simultaneously with antiretroviral therapy were impaired compared to patients not taking methadone oral solution: $\mathrm{C}_{\min }=315$ (range 197-448) vs. 519 (279-793) ng/mL [GM ratio $(\mathrm{GMR})=0.61, p=0.229] ; \mathrm{C}_{\max }=1714 \quad(1238-2262)$
\end{abstract}

A. Haberl • M. Moesch • G. Nisius · C. Stephan • M. Bickel • P. Khaykin $\cdot$ R. Brodt $\cdot$ N. von Hentig $(\bowtie)$

HIVCENTER, Medical Clinics II,

J.W.Goethe University Hospital,

Frankfurt am Main, Germany

e-mail: Hentig@em.uni-frankfurt.de

M. Kurowski

HIVLab, Auguste-Viktoria-Hospital,

Berlin, Germany vs. $3190(2412-4076) \mathrm{ng} / \mathrm{mL}(\mathrm{GMR}=0.54, p=0.018)$; $\mathrm{AUC}=21,987(15,870-29,327)$ vs. $35,572(26,211-46,728)$ $\mathrm{ng} \mathrm{h} / \mathrm{mL}(\mathrm{GMR}=0.62, p=0.074)$. Methadone dose, which is proportional to the amount of methadone oral solution $(10 \mathrm{mg} / \mathrm{mL})$, was significantly correlated to atazanavir $\mathrm{C}_{\max }$ $\left(r^{2}=0.40, p=0.001\right)$ and AUC $\left(r^{2}=0.32, p=0.006\right)$. Ritonavir pharmacokinetics was similar between the groups with $\mathrm{C}_{\min }$, $\mathrm{C}_{\max }$, and AUC GMR of 1.01, 0.80, and 0.96, respectively. Conclusion The partial decrease in atazanavir plasma concentrations in patients concomitantly taking racemic methadone oral solution in this daily observed therapy setting deserves further attention, and therapeutic drug monitoring should be considered.

Keywords Atazanavir · HIV - Low-dose ritonavir · Methadone maintenance therapy · Pharmacokinetics . Protease inhibitor

\section{Introduction}

Amongst other currently available human immunodeficiency virus (HIV) protease inhibitors, atazanavir is approved for the once-daily administration in HIV therapy [1]. Consequently, ritonavir-boosted atazanavir is used as a component of daily observed therapies concomitantly administered with a methadone oral solution as opiate substitution maintenance therapy. Previous study results have not revealed an impact of methadone on the pharmacokinetics of atazanavir and vice versa $[7,15,17]$. However, during a routine analysis of data from the pharmacokinetic database of the Frankfurt HIV cohort, we detected lower atazanavir plasma concentrations in patients taking a methadone oral solution than that in the general population. 
Against the background of these findings, we (1) compared the pharmacokinetics of a combination of atazanavir and lowdose ritonavir in 12 adult outpatients (6 men, 6 women) concomitantly taking methadone maintenance therapy to a random sample of patients matched for gender, age, weight, and ethnicity and who did not take methadone and (2) correlated the results with demographic and clinical co-factors which potentially may alter the pharmacokinetics of atazanavir/ ritonavir. Virologic and immunologic response as well as side effects are also described.

\section{Patients and methods}

\section{Patients}

Twenty-four patients infected with HIV-1 received a combination of atazanavir/ritonavir 300/100 mg once daily plus at least two nucleoside/nucleotide reverse transcriptase inhibitors as first- or second-line therapy.

Protease inhibitor therapy-experienced patients $(n=10)$ were selected for the atazanavir/ritonavir plus NRTI therapy regimen, provided that the interpretation of genotypic resistance testing [10] asserted sufficient susceptibility of the HIV-1 virus to the compounds. There was no CD4 cell count or viral load restriction included in this study. Patients completed a 24-h pharmacokinetic assessment according to a standardized therapeutic drug monitoring (TDM) protocol that is used for all outpatients [14]. Pharmacokinetic data were assessed from all patients who started on antiretroviral therapy (ART) containing atazanavir/ ritonavir as first-line therapy in June 2003 and participated in routine TDM procedures until June 2006 and who concomitantly were taking a methadone oral solution as opiate substitution therapy. At that time, ritonavir-boosted atazanavir was not approved for first-line therapy in the European Union. These patients participated in the 3ODstudy, and the clinical data of this study have been presented previously $[5,6]$. The study procedures of the 3OD study included pharmacokinetic assessment over a 24-h period. However, since 2001, it has been the standard clinical procedure of our outpatient center to perform a pharmacokinetic assessment of patients receiving first-line ART after at least 2 weeks on therapy and of patients switching their ART to a second or third regimen. Data on these patients were compared to a random sample of patients who did not take concomitant methadone and who were matched for gender, age, weight, and ethnicity. The matching procedure allowed maximum deviations of age and weight between two samples of $\pm 5 \%$. These patients took ritonavir-boosted atazanavir as a second-line therapy according to the actual guidelines. Patients in the control group took no injection drugs or drug substitution of any other kind.
Patients with hepatic impairment defined by Child-Pugh classification $\mathrm{B}$ or $\mathrm{C}$, patients receiving co-medication with cytochrome P350 (CYP) 3A4/5 enzyme inhibitors/inducers, and patients taking antiacids were not included in the analyses.

The 3OD-study complied with the Declaration of Helsinki. The study was approved by the responsible authorities, and all patients provided written informed consent. Data on the matched pair samples were obtained during routine clinical procedures. Hence, no additional intervention was performed in these patients, and ethics approval was not obtained in accordance with the national laws of Germany and previously obtained advice from the responsible institutional Ethics Committee of the Johann Wolfgang Goethe-University, Frankfurt am Main. All patients were individually informed and trained in the TDM procedure and agreed to their data being recorded, which were subsequently anonymized for this analysis. TDM training includes providing the patient with written and verbal information focusing on the adherence to drug intake in defined dosing intervals at least 3 days prior to the pharmacokinetics (pk) day for assuring steady-state conditions, the documentation of all concomitant drug intake including nutritive and herbals and the adherence to the protocol of the pk-day itself.

\section{Therapeutic drug monitoring protocol}

After at least 4 weeks on the regimen, patients underwent a pharmacokinetic assessment following a standardized protocol at steady-state conditions. The schedule of drug intake was documented by the patients for 3 days prior to the pharmacokinetic assessment. In addition, all concomitant drug application had to be documented by the patient and physician, including the daily intake of herbal agents or nutritive supplements. On the day of the pharmacokinetic assessment, fasting trough levels were obtained immediately before drug intake, followed by a standardized breakfast of approximately $2500 \mathrm{~kJ}$ ( $25 \%$ from fat). Plasma samples were then collected at $1,2,4,6,9,12$, and $24 \mathrm{~h}$ after the drug intake. Patients stayed $12 \mathrm{~h}$ in house and returned the next morning for the $24 \mathrm{~h}$-assessment.

Pharmacokinetic assay and evaluation

Atazanavir and ritonavir plasma concentrations were measured by validated high-pressure liquid chromatographytandem mass spectrometry methods (equipment from Merck-Hitachi, Germany and Applied Biosystems, Canada from Therapia $\mathrm{GmbH}$, Berlin, Germany), which are described elsewhere [11]. The reliable lower limit of quantification (LLQ) was $20 \mathrm{ng} / \mathrm{ml}$, and the linearity of the calibration curve for all tested compounds has been proven up to $20,000 \mathrm{ng} / \mathrm{ml}$. 
Pharmacokinetic calculations were based on plasma concentrations which exceeded the LLQ. The serum plasma $\mathrm{C}_{\min }$ (trough concentration) and $\mathrm{C}_{\max }$ (peak concentration) values of the non-compartmental analysis were read directly from the plasma concentration-time curves of atazanavir and ritonavir within the standard dosing interval $(\tau=0-24 \mathrm{~h})$. The area under the plasma concentration-time curve, $\operatorname{AUC}_{(\tau)}$, at steady state, the elimination half-life, $t_{1 / 2}$, and the total clearance, $\mathrm{CL}_{\text {total }}$ were obtained by using a noncompartmental analysis module (TopFit ver. 2.0; Thomae, Langenselbold, Germany).

\section{Statistical methods}

The primary target variables, $\mathrm{C}_{\min }, \mathrm{C}_{\max }, \mathrm{AUC}_{(\tau)}, \mathrm{CL}_{\text {tot }}$, and $t_{1 / 2}$ of atazanavir and ritonavir were compared between matched pairs of samples by means of $t$ tests. The absence of a significant difference of the atazanavir and ritonavir exposure between groups was suggested when no significant difference (at a 0.05 -level) of the geometric mean ratio (GMR), together with a $90 \%$ confidence interval (CI), was determined. This procedure follows the U.S. Federal Drug Administration recommendations for the conduct of clinical pharmacokinetic drug interaction studies [2]. The correlation analysis (Spearman's $\rho$ ) was set to a significance level of 0.001 level after Bonferroni-correction (SPSS ver. 16.0 for Windows; SPSS, Chicago, IL).

\section{Results}

\section{Patients' disposition}

No statistically significant differences were present with respect to the baseline characteristics of patients taking or not taking methadone: baseline $[ \pm$ standard error of mean (SEM)] age, weight, and atazanavir dose/weight were 37.4 $( \pm 1.8)$ versus $38.7( \pm 1.8)$ years $(p=0.633), 73.5( \pm 5.2)$ versus $71.8( \pm 4.4) \mathrm{kg}(p=0.814)$, and $4.31( \pm 0.32)$ versus $4.37( \pm 0.29) \mathrm{mg} / \mathrm{kg}$ bodyweight $(p=0.884)$, respectively. The time since the first HIV diagnosis was $109( \pm 12)$ versus $94( \pm 18)$ months in the methadone group and control subjects not taking methadone, respectively $(p=0.492)$. Although seven patients in the methadone group (58.3\%) and four patients $(33.3 \%)$ in the random sample were hepatitis-C virus-PCR positive $(p=0.090)$, none of these patients showed signs of hepatic impairment according to the Child-Pugh criteria. The mean number of previous antiretroviral therapies was 5.0 (methadone group) versus 4.2 (non-methadone group) $(\mathrm{p}=0.575)$, and the mean number of patients having taken one protease inhibitor previously was equal for both groups. The mean $( \pm$ SEM) baseline CD4 cell count was $307( \pm 84)$ versus $254( \pm 57)$ cells $/ \mu \mathrm{L}(p=0.608)$ and mean viral load was $3.95( \pm 0.44)$ versus $4.02( \pm 0.42) \log { }_{10}$ copies $/ \mathrm{mL}(p=0.916)$ for the methadone group and non-methadone group, respectively, and did not differ significantly between groups.

In terms of concomitantly taken drugs, patients from the methadone and non-methadone group received tenofovirDF (either as Truvada or Viread; Gilead Sciences, Foster City, CA; 12 vs. 8 , respectively), emtricitabine (either as Truvada or Emtriva; Gilead Sciences; 7 vs. 3, respectively), lamivudine (Epivir; GlaxoSmithKline, London, UK; 2 vs. 3, respectively), didanosine (Videx; Bristol Myers Squibb, New York, USA; 3 vs. 6, respectively), zidovudine (Retrovir; GlaxoSmithKline; 0 vs. 2, respectively), stavudine (Zerit; Bristol Myers Squibb; 0 vs. 1, respectively), and cotrimoxazole (CotrimHEXAL; Hexal, Holzkirchen, Germany; 4 vs. 3 , respectively). None of these drugs appeared to be confounders altering the protease inhibitor plasma concentrations in the analysis of variance (ANOVA) analysis.

\section{Pharmacokinetic analysis}

The analysis of the six men and six women taking methadone versus the 12 control subjects not taking methadone revealed substantial differences: the geometric mean $(90 \% \mathrm{CI})$ of the atazanavir $\mathrm{C}_{\min }, \mathrm{C}_{\max }, \mathrm{AUC}$, and $\mathrm{CL}_{\text {total }}$ were 315 (197-448) versus 519 (279-793) ng/mL $(p=0.229), 1714(1238-2262)$ versus $3190(2412-4076)$ $\mathrm{ng} / \mathrm{mL}(p=0.018), 21987(15,870-29,327)$ versus 35,572 $(26,211-46,728) \mathrm{ng} \mathrm{h} / \mathrm{mL}(p=.0 .074)$, and $227(161-298)$ versus $141(102-183) \mathrm{mL} / \mathrm{min}(p=0.074)$, respectively [Table 1].

Interestingly, the correlation analyses showed statistically significant correlations between methadone dose and atazanavir $\mathrm{C}_{\max }$ (Spearman's $\left.\rho, r^{2}=0.40, p<.0 .001\right)$ and $\operatorname{AUC}\left(r^{2}=0.32, p=0.006\right)$ (Fig. 1).

A subsequent linear regression analysis with the backward deletion of variables focused on the correlation between atazanavir $\mathrm{C}_{\min }$, which was chosen as the most relevant parameter for therapy outcome, and covariables that previously were either correlated (Spearman's $\rho$ ) to atazanavir plasma concentration or significantly different between the groups in the univariate analyses, $t$ tests or chi $^{2}$-tests, respectively. The final regression model presented the following parameters as being correlated to the atazanavir $\mathrm{C}_{\min }$ : ritonavir $\mathrm{C}_{\min }(p<0.001)$, methadone intake $(p<0.006)$, time since first diagnosis of HIV $(p=0.015)$, and age $(p=0.022)$.

\section{Clinical results}

The clinical results showed a comparable efficacy of therapy between both groups (Fig. 2): of the 12 patients taking concomitantly methadone (group 1), seven were on 
Table 1 Protease inhibitor pharmacokinetics of 24 patients taking atazanavir/ritonavir 300/100 mg once-daily plus nucleoside/ nucleotide reverse transcriptase inhibitors, either together with daily methadone doses of $20-175 \mathrm{mg}$ (mean $90 \mathrm{mg}, n=12$ ) or without methadone $(n=12)$, matched pair-wise for age, gender, weight, and ethnicity

\begin{tabular}{|c|c|c|c|c|}
\hline Pharmacokinetic parameters & $\begin{array}{l}\text { w/+ methadone } \\
\text { (group } 1 ; n=12 \text { ) }\end{array}$ & $\begin{array}{l}\text { w/- methadone } \\
\text { (group } 2 ; n=12 \text { ) }\end{array}$ & $\begin{array}{l}\text { Difference between } \\
\text { group } 1 \text { vs. group } 2\end{array}$ & $t$ test: $p$ value \\
\hline
\end{tabular}

$$
\begin{aligned}
& \text { Atazanavir } \\
& \mathrm{C}_{\min }(\mathrm{ng} / \mathrm{mL}) \\
& \mathrm{C}_{\max }(\mathrm{ng} / \mathrm{mL}) \\
& \mathrm{AUC}(\mathrm{ng} * \mathrm{~h} / \mathrm{mL}) \\
& \mathrm{t}_{1 / 2}(\mathrm{~h}, \mathrm{~min}) \\
& \mathrm{CL}_{\text {total }}(\mathrm{mL} / \mathrm{min}) \\
& \text { Ritonavir } \\
& \mathrm{C}_{\min }(\mathrm{ng} / \mathrm{mL}) \\
& \mathrm{C}_{\max }(\mathrm{ng} / \mathrm{mL}) \\
& \mathrm{AUC}(\mathrm{ng} * \mathrm{~h} / \mathrm{mL}) \\
& \mathrm{t}_{1 / 2}(\mathrm{~h}, \mathrm{~min}) \\
& \mathrm{CL}_{\text {total }}(\mathrm{mL} / \mathrm{min})
\end{aligned}
$$$$
315(197-448)
$$$$
1,714(1238-2262)
$$$$
\text { 21,987 (15870-29327) }
$$$$
8.58(7.29-9.71)
$$$$
227(161-298)
$$

$519(279-793)$
$3,190(2412-4076)$
$35,572(26211-46728)$
$7.29(6.21-8.23)$
$141(102-182)$
$67(42-91)$
$1,134(868-1429)$
$9,760(7416-12462)$
$4.28(3.78-4.60)$
$171(128-216)$

$\begin{array}{ll}0.61(0.56-0.71) & 0.229 \\ 0.54(0.51-0.56) & 0.018 \\ 0.62(0.60-0.63) & 0.074 \\ 1.18(1.17-1.18) & 0.196 \\ 1.61(1.57-1.64) & 0.074 \\ & \\ 1.01(0.93-1.07) & 0.972 \\ 0.80(0.64-0.93) & 0.470 \\ 0.96(0.86-1.05) & 0.889 \\ 1.37(1.27-1.46) & 0.015 \\ 1.04(0.91-1.12) & 0.889\end{array}$

w/+, With; w/-, without; GeoMean, Geometric mean; CI, Confidence interval; $\mathrm{C}_{\min }$, minimum plasma concentration within the dosing interval; $\mathrm{C}_{\max }$, maximum plasma concentration within the dosing interval; $\mathrm{AUC}$, area under the concentration-time curve; $\mathrm{t}_{1 / 2}$, half life; $\mathrm{Cl}_{\text {total }}$, total oral clearance

Values are given as the GeoMean, with the $90 \%$ CI given in parenthesis

therapy at week 48 compared to eight patients not taking methadone (group 2). The mean $(95 \% \mathrm{CI}) \mathrm{CD} 4$ cell count was $427 / \mu \mathrm{L}(269-585)$ in group 1 compared to $445 / \mu \mathrm{L}$ (397-490) in group 2. The mean $(95 \% \mathrm{CI}) \log _{10}$ HIV-RNAPCR was $1.656 / \mathrm{mL}(1.542-1.770)$ in group 1 compared to $\left(\log _{10}\right) 1.590 / \mathrm{mL}(1.590)$ in group 2 at week 48 of therapy. Reasons for therapy interruption in group 1 prior to week 48 were virologic failure, presumably due to non-compliance $(n=1)$, and unwanted adverse drug reactions $(n=4)$; in group 2 , it was also virologic failure $(n=1)$ and unwanted adverse drug reactions $(n=2)$. Adverse drug reactions consisted of gastrointestinal side effects and diarrhea $(n=4)$, thrombocytopenia $(n=3)$, and one case each of anemia, hypertrichosis, loss of libido, and hyperbilirubinemia. The overall incidence of adverse drug reactions of grade 3-4 was low: the three cases of thrombocytopenia and one case of anemia were probably related to the nucleoside reverse transcriptase inhibitor co-medication and did not result in therapy interruption. In the case of anemia, zidovudine/lamivudine were switched to tenofovir-DF/emtricitabine, while atazanavir/ritonavir were continued.

\section{Conclusion}

An analysis of the atazanavir pharmacokinetics of patients taking a methadone oral solution from the pharmacokinetic database of the Frankfurt HIV cohort detected low atazanavir plasma concentrations in these patients. Although previous studies failed to show pharmacokinetic interactions between methadone and atazanavir/ritonavir [7, 15, we performed an analysis of patient pairs, matched for gender, age, ethnicity and weight, in order to exclude a demographic bias. The results of our analysis confirmed the distinct and statistically significant differences in atazanavir pharmacokinetics between patients with or without methadone co-medication. As methadone is known to be a substrate without inducing potency regarding the activity of CYP2B6, $-2 \mathrm{C} 9,-2 \mathrm{C} 19$, $-2 \mathrm{D} 6$, and $-3 \mathrm{~A} 4$, and the main metabolic pathway of atazanavir is CYP3A, our results suggest that concomitant methadone intake may impair the plasma concentrations of atazanavir and ritonavir for other, as yet unknown reasons. Friedland et al. also measured atazanavir plasma concentrations in the presence of methadone and found no difference compared to previously reported values, even if atazanavir was taken unboosted at a daily dose of $400 \mathrm{mg}$ [7]. In the presence of ritonavir, which is a very potent inhibitor of CYP3A, any possible effects of methadone on CYP3 metabolism of atazanavir are most likely to be superimposed. Previous studies with, for example, nelfinavir have not shown any influence of methadone on the metabolism of HIV protease inhibitors [9].

We found that age, weight, gender, and ethnicity were not confounders in this analysis. The adherence of patients taking methadone was documented in the 3OD-study by patients and physicians and indirectly confirmed by ritonavir plasma concentrations, which were similar to those of patients who did not take methadone. 

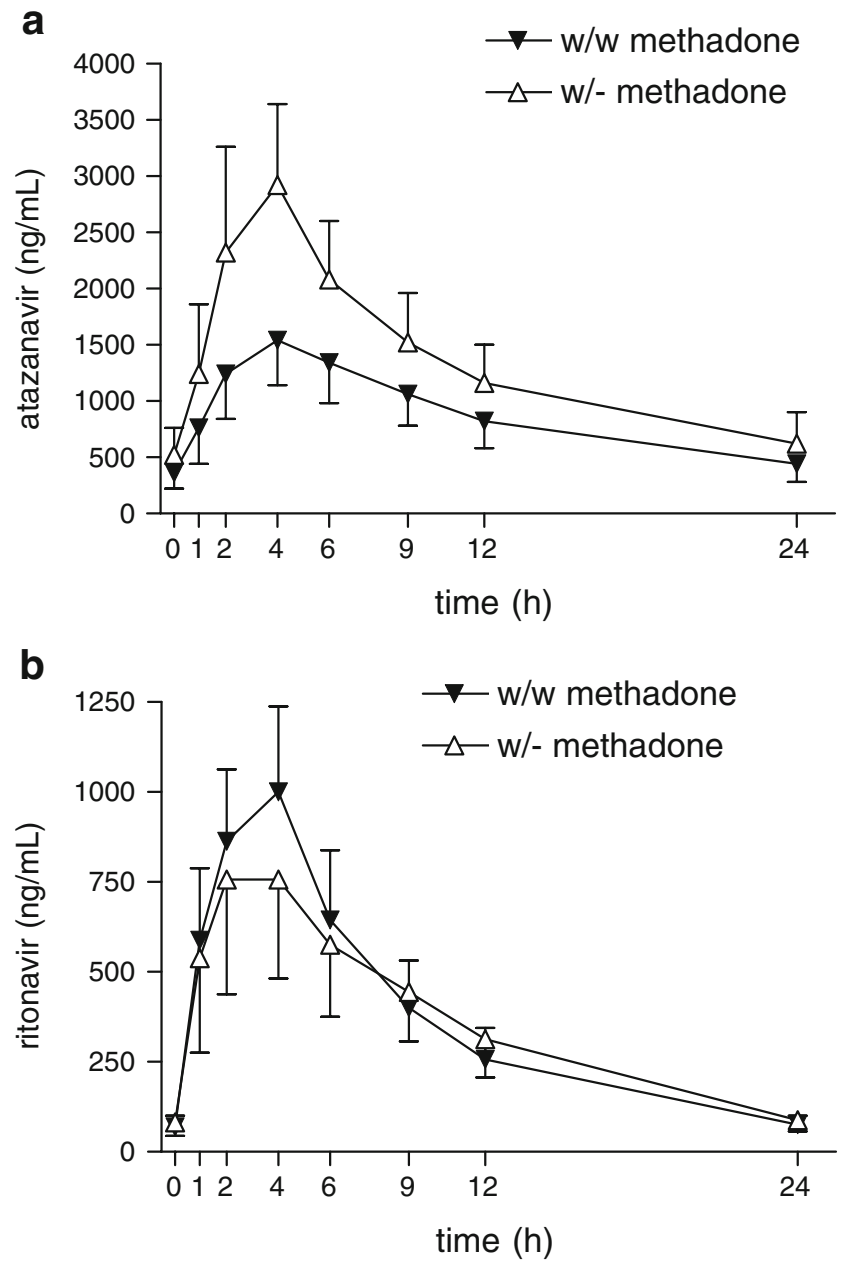

w/w = with; w/- = without;

Fig. 1 Atazanavir (a) and ritonavir (b) plasma concentration versus time curve in patients $(n=12)$ concomitantly taking methadone oral solution, compared to patients $(n=12)$ not taking methadone. Patients were matched pair-wise for age, gender, weight and ethnicity

One potential reason for this clinically relevant finding may be a formulation-based influence of the oral methadone solution on the absorption of atazanavir. The methadone oral solution is a hydrochloride solution, which improves its absorption but does not increase stomach $\mathrm{pH}$; an increased stomach $\mathrm{pH}$ is regarded being one possible reason for the impeded absorption of atazanavir. However, in Germany, the methadone oral solution contains a number of ingredients that are added to the racemic methadone in order to avoid the abusive injection of the opiate substitute intravenously, which is not allowed according to federal laws. A $10-\mathrm{ml}$ aliquot of methadone oral solution $(100 \mathrm{mg}$ racemic methadone) contains $8.0 \mathrm{~g}$ of a viscose basic solution with, for example, $50.0 \mathrm{mg}$ hydroxyethylcellulose 400, $2.0 \mathrm{~g}$ glycerol $85 \%$, and, as aroma-color concentrates, chinolin yellow and contramarum. It is possible that the viscous liquid formulation impedes the absorption of atazanavir by forming dissoluble complexes with atazanavir to some extent in the stomach, when administered at the same time. In general, the combination of atazanavir/ ritonavir is a pharmacokinetically safe regimen which shows little pharmacokinetic differences between gender and is not affected by demographic differences, such as age, gender, weight, or tenofovir co-medication [18, 19], which can affect the pharmacokinetics of other protease inhibitors [16], such as lopinavir [3], amprenavir [8], or saquinavir

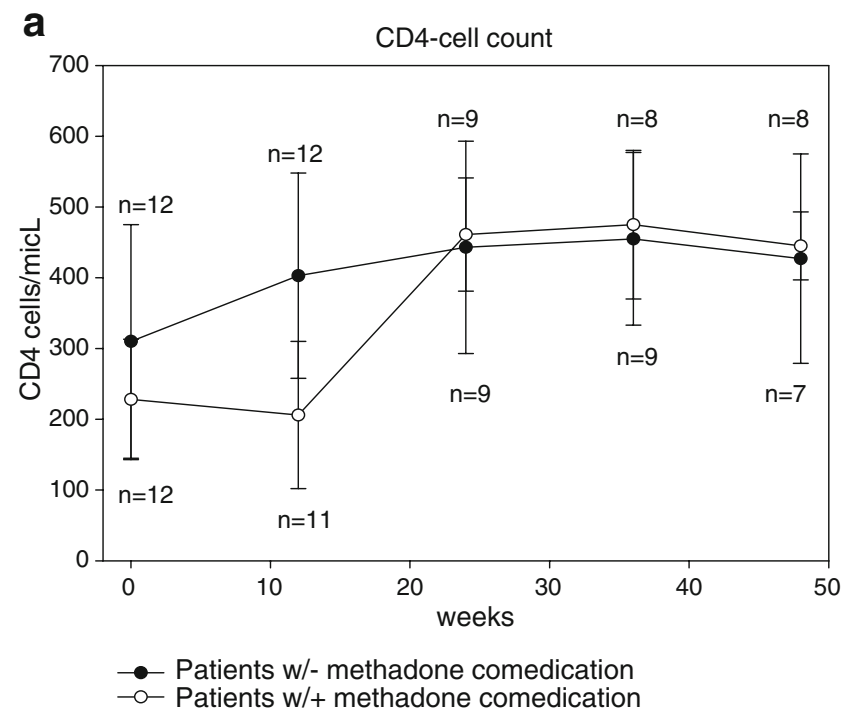

b

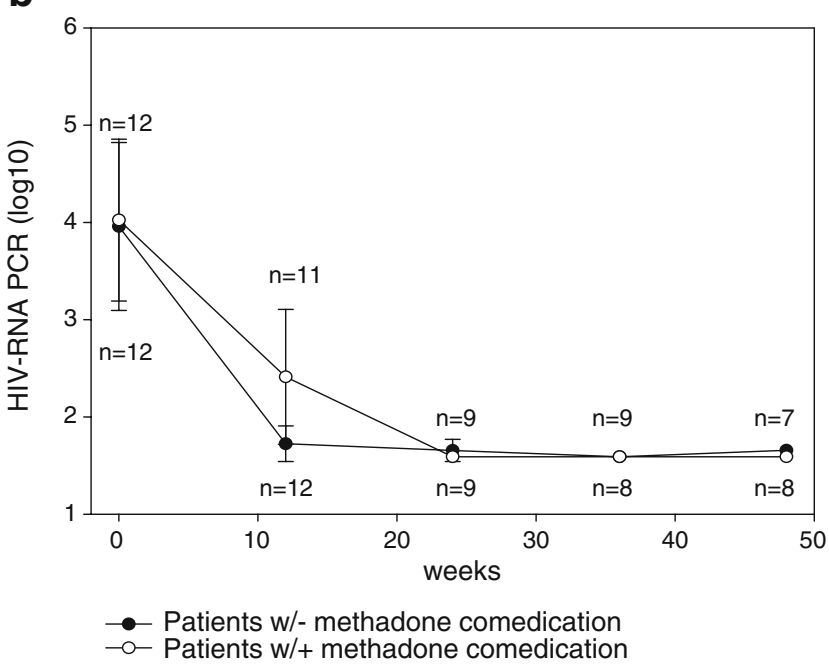

$\mathrm{w} /+=$ with; $\mathrm{w} /-=$ without;

Fig. 2 CD4 cell count (a) and human immunodeficiency virus (HIV) load (b) through to week 48 of therapy with atazanavir/ritonavir 300/ $100 \mathrm{mg}$ once-daily plus nucleoside reverse transcriptase inhibitors in patients $(n=12)$ concomitantly taking methadone oral solution, compared to patients $(n=12)$ not taking methadone. Patients were matched pair-wise for age, gender, weight and ethnicity 
[13]. It often is used in situations where a once-daily (observed) application of ART is warranted. This usage is supported by its combinability with once-daily nucleoside/ nucleotide reverse transcriptase inhibitors, such as tenofovirDF [19] and emtricitabine. The substitute opiate buprenorphine $[4,12]$ can also be co-administered without altering the pharmacokinetics of atazanavir/ritonavir.

However, the cases of patients reported here show that the intake of oral methadone solution may have an impact on the pharmacokinetic parameters of ritonavir-boosted atazanavir. In terms of patients receiving a combination of ritonavir-boosted atazanavir and methadone oral solution, the results presented here suggest that the atazanavir plasma concentrations should be monitored frequently to ensure that the plasma concentrations are sufficient for sustaining the antiviral efficacy of this regimen. The comparably low atazanavir $\mathrm{C}_{\min }$ within the dosing interval may impede the forgiveness of this regimen; for example, if one dose is missed or a dosing interval is prolonged, atazanavir plasma concentrations may fall below the recommended $150 \mathrm{ng} / \mathrm{mL}$ in vivo, which is considered the plasma protein binding corrected effective concentration against wild-type HIV at an in vitro $90 \%$ inhibitory concentration of 5-15 $\mathrm{nM}$ [17].

Given the small number of patients in our study and taking previous study results into account that did not report such an interaction between atazanavir and methadone tablets, the use of a combined atazanavir/ritonavir and methadone should not be disregarded. Also, the antiviral efficacy and the incidence of adverse drug reactions over 48 weeks of therapy were comparable in both groups of patients - those patients who took methadone oral solution and those who did not.

This study has a number of limitations. First, a sample size estimation was not performed due to the restricted number of samples from opiate substituted patients. Secondly, the methadone plasma concentrations were not measured, and the methadone effects on atazanavir exposure could only be correlated to the methadone dose and not the methadone plasma concentration. However, the results can be of clinical relevance for a long-term antiretroviral therapy and a drug-drug interaction between methadone, if applied as an oral solution, and boosted atazanavir should be taken into account at this stage of investigation, and the substantially decreased atazanavir plasma concentrations deserve further attention in oncedaily observed therapy settings.

Funding This pharmacokinetic analysis was supported by internal funds.

Transparency declaration None to declare

\section{References}

1. Bristol Myers Squibb Company (2007) Reyataz product information. NDA 21-567/S-012. Bristol Meyers Squib, Princeton, NJ

2. CBER (1999) Guidance for the industry. In vivo drug metabolism/ drug interactions studies. Study design, data analysis and recommendations for dosing and labeling. Center for Biologics Evaluation and Research (CBER), Rockville

3. Burger DM, Muller RJ, van der Leur MR, la Porte CJL (2002) Lopinavir plasma levels are significantly higher in female than in male HIV-1 infected patients. In: Program and abstracts of the 3rd Int Workshop Clinical Pharmacology of HIV Therapy. Washington D.C.

4. DiFrancesco R, Fischl MA, Donnelly J, Zingman BS, McCance-Katz EF, Moody DE, Reichman RC, Gripshover B, Morse GD (2007) Buprenorphine assay and plasma concentration monitoring in HIV-infected substance users. J Pharm Biomed Anal 44:188-195

5. Esser S, Staszewski S, Haberl A, Mulcahy F, Gölz J, Lazzarin A, Teofilo E, Vera J, Körber A, Ranneberg B, Gallo L (2008) 3ODOnce-daily (OD) TDF-containing HAART in HIV-1-infected former IVDU-patients receiving opiate substitution: efficacy, tolerability and adherence. In: 9th Int Congress Drug Therapy in HIV Infection. Glasgow

6. Esser S, Staszewski S, Haberl A, Mulcahy F, Gölz J, Lazzarin A, Teofilo E, Vera J, Körber A, Ranneberg B, Gallo L (2008) An open-label multicenter study to assess efficacy, tolerability and adherence of a once-daily (OD) TDF-Containing HAART in HIV1-Infected Former IVDU-Patients receiving opiate substitutionfinal 48 weeks analysis of 3OD. In: 17th International AIDS Conference. Mexico City, Mexico

7. Friedland G, Andrews L, Schreibman T, Agarwala S, Daley L, Child M, Shi J, Wang Y, O'Mara E (2005) Lack of an effect of atazanavir on steady-state pharmacokinetics of methadone in patients chronically treated for opiate addiction. Aids 19:16351641

8. Gatti G, De Pascalis CR, De Luca A et al (2002) Predictors of amprenavir parameters of drug exposure in heavily pretreated HIV positive patients (abstract). In: Proc 6th Int Congress in Drug Therapy in HIV Infection. Glasgow, p 165

9. Hsyu PH, Lillibridge J, Daniels E, Kerr BM (2006) Pharmacokinetic interaction of nelfinavir and methadone in intravenous drug users. Biopharm Drug Dispos 27:61-68

10. Johnson V, Brun-Vezinet F, Clotet B, Conway B, Kuritzkes D, Pillay D, Schapiro J, Telenti A, Richman D (2005) Update of the drug resistance mutations in HIV-1: 2005. Topics HIV Med 13:125-131

11. Kurowski M, Sternfeld T, Sawyer A, Hill A, Mocklinghoff C (2003) Pharmacokinetic and tolerability profile of twice-daily saquinavir hard gelatin capsules and saquinavir soft gelatin capsules boosted with ritonavir in healthy volunteers. HIV Med 4:94-100

12. McCance-Katz EF, Moody DE, Morse GD, Ma Q, Difrancesco R, Friedland G, Pade P, Rainey PM (2007) Interaction between buprenorphine and atazanavir or atazanavir/ritonavir. Drug Alcohol Depend 91:269-278

13. Pai MP, Schriever CA, Diaz-Linares M, Novak RM, Rodvold KA (2004) Sex-related differences in the pharmacokinetics of oncedaily saquinavir soft-gelatin capsules boosted with low-dose ritonavir in patients infected with human immunodeficiency virus type 1. Pharmacotherapy 24:592-599

14. Stephan C, Hentig N, Kourbeti I, Dauer B, Mosch M, Lutz T, Klauke S, Harder S, Kurowski M, Staszewski S (2004) Saquinavir drug exposure is not impaired by the boosted double protease inhibitor combination of lopinavir/ritonavir. Aids 18:503-508 
15. Tossonian HK, Raffa JD, Grebely J, Trotter B, Viljoen M, Mead A, Khara M, McLean M, Duncan F, Fraser C, DeVlaming S, Conway B (2007) Methadone dosing strategies in HIV-infected injection drug users enrolled in a directly observed therapy program. J Acquir Immune Defic Syndr 45:324-327

16. Umeh O, Currier J (2006) Sex differences in the pharmacokinetics and toxicity of antiretroviral therapy. Expert Opin Drug Metab Toxicol 2:273-283

17. von Hentig N (2008) Atazanavir/ritonavir: a review of its use in HIV therapy. Drugs Today (Barc) 44:103-132
18. von Hentig N, Babacan E, Stephan C, Lennemann T, Knecht G, Carlebach A, Harder S, Staszewski S, Haberl A (2008) Pharmacokinetics of atazanavir/ritonavir in HIV-1 infected adult outpatients is not affected by gender-related cofactors. J Antimicrob Chemother 62:579-582

19. von Hentig N, Dauer B, Haberl A, Klauke S, Lutz T, Staszewski S, Harder S (2007) Tenofovir comedication does not impair the steady-state pharmacokinetics of ritonavirboosted atazanavir in HIV-1-infected adults. Eur J Clin Pharmacol 63:935-940 